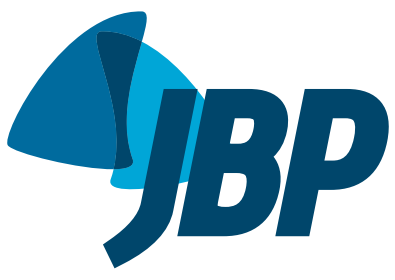

\title{
Presence of gas in an unusual place: spontaneous pneumomediastinum (Hamman's syndrome)
}

\author{
Nicholas Oliveira Duarte ${ }^{1, a}$, Camila Hino Verdelho ${ }^{1, b}$, Rodolfo Mendes Queiroz ${ }^{2,3, c}$
}

A 19-year-old male patient complained of coughing without expectoration, mild dyspnea, and retrosternal pain for three days, with no history of trauma. At physical examination, the patient presented with mild dyspnea, with no evidence of bruising or open cutaneous wounds, mildly painful crackles on bilateral supraclavicular and anterior cervical palpation, and no abnormalities on lung auscultation or laboratory test results. Chest HRCT scans revealed the presence of gas foci in the mediastinum that extended to the neck (Figure 1, arrows), which was compatible with spontaneous pneumomediastinum (Hamman's syndrome). This is a benign, usually selflimiting disease ${ }^{(1)}$ that is more common in male patients from 17 to 25 years of age and slender body type ${ }^{(2)}$ and is characterized by the presence of air in the mediastinum that is unrelated to trauma ${ }^{(3)}$; the prognosis is usually excellent with conservative treatment, i.e., symptomatic treatment based on analgesia, oxygen therapy, and rest.

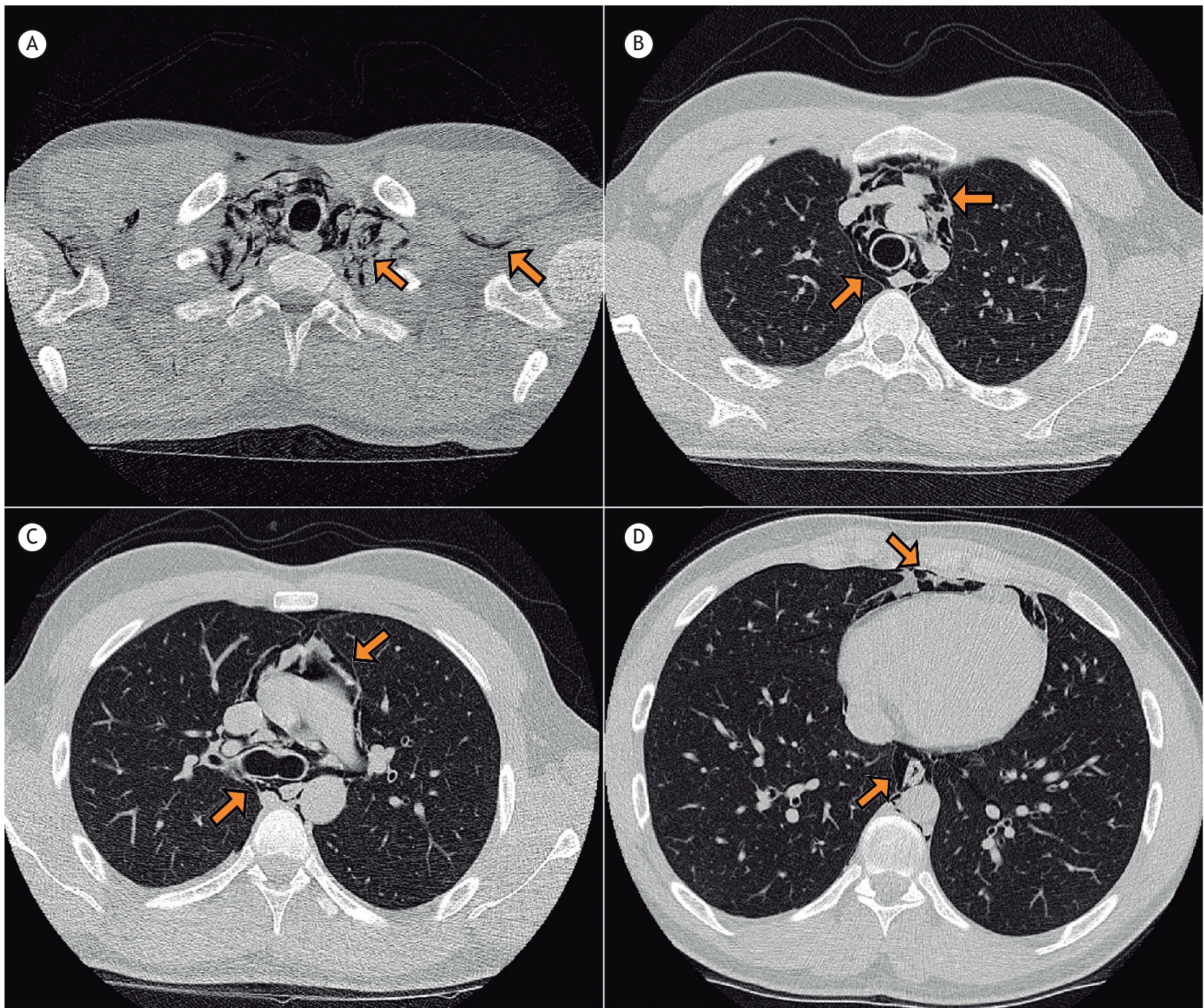

Figure 1. HRCT scans using axial sections, filter and lung window settings, showing the presence of laminar images with marked hypoattenuation representing gas (arrows) in deep topographies in the cervicothoracic transition and axillary regions (in A), as well as in mediastinal, paraesophageal, and paracardiac sites (in B, C and D, respectively).

\section{REFERENCES}

1. Fishman AP, Elias JA, Fishman JA, Grippi MA, Senior RM, Pack Al. Fishman's Pulmonary Disease and Disorders. 4th ed. Philadelphia: McGraw-Hill Medical; 2008.

2. 2. Fatureto $M C$, Santos JP, Goulart PE, Maia S. Spontaneous pneumomediastinum: asthma [Article in Portuguese]. Rev Port Pneumol. 2008:14(3):437-41. https://doi.org/10.1016/S0873-2159(15)30251-8

3. 3. Hamman L. Spontaneous mediastinal emphysema. Bull Johns Hopkins Hosp. 1939;64(1):1-21

1. Imagem Center - Diagnóstico por imagem. Departamento de Radiologia e Diagnóstico por Imagem, São José do Rio Preto (SP) Brasi

2. CENTROMED - Diagnóstico por imagem. Departamento de Radiodiagnóstico, Avaré (SP) Brasil.

3. Hospital da Santa Casa de Misericórdia de Avaré, Avaré (SP) Brasil.

a. (D) http://orcid.org/0000-0002-3415-8207; b. (D) http://orcid.org/0000-0002-9172-5095; c. (D) http://orcid.org/0000-0002-4893-4422 